\title{
Time-driven activity-based costing: a driver for provider engagement in costing activities and redesign initiatives
}

\author{
Nancy McLaughlin, M.D., Ph.D., F.R.C.S.C., ${ }^{1}$ Michael A. Burke, M.H.A., ${ }^{2}$ \\ Nisheeta P. Setlur, M.B.A., ${ }^{2}$ Douglas R. Niedzwiecki, M.B.A., M.H.A., ${ }^{3}$ \\ Alan L. Kaplan, M.D. ${ }^{4}$ Christopher Saigal, M.D., M.P.H. ${ }^{4}$ \\ Aman Mahajan, M.D., Ph.D., ${ }^{5}$ Neil A. Martin, M.D., ${ }^{1}$ and Robert S. Kaplan, Ph.D. ${ }^{6}$
}

Departments of ${ }^{1}$ Neurosurgery, ${ }^{3}$ Operative Services, ${ }^{4}$ Urology, and ${ }^{5}$ Anesthesia, David Geffen School of Medicine at UCLA; ${ }^{2}$ Department of Performance Excellence, UCLA Health, Los Angeles, California; and ${ }^{6}$ Harvard Business School, Boston, Massachusetts

\begin{abstract}
Object. To date, health care providers have devoted significant efforts to improve performance regarding patient safety and quality of care. To address the lagging involvement of health care providers in the cost component of the value equation, UCLA Health piloted the implementation of time-driven activity-based costing (TDABC). Here, the authors describe the implementation experiment, share lessons learned across the care continuum, and report how $\mathrm{TDABC}$ has actively engaged health care providers in costing activities and care redesign.

Methods. After the selection of pilots in neurosurgery and urology and the creation of the TDABC team, multidisciplinary process mapping sessions, capacity-cost calculations, and model integration were coordinated and offered to engage care providers at each phase.

Results. Reviewing the maps for the entire episode of care, varying types of personnel involved in the delivery of care were noted: 63 for the neurosurgery pilot and 61 for the urology pilot. The average cost capacities for care coordinators, nurses, residents, and faculty were $\$ 0.70$ (range \$0.63-\$0.75), \$1.55 (range \$1.28-\$2.04), \$0.58 (range $\$ 0.56-\$ 0.62$ ), and \$3.54 (range \$2.29-\$4.52), across both pilots. After calculating the costs for material, equipment, and space, the TDABC model enabled the linking of a specific step of the care cycle (who performed the step and its duration) and its associated costs. Both pilots identified important opportunities to redesign care delivery in a costconscious fashion.

Conclusions. The experimentation and implementation phases of the TDABC model have succeeded in engaging health care providers in process assessment and costing activities. The TDABC model proved to be a catalyzing agent for cost-conscious care redesign.
\end{abstract}

(http://thejns.org/doi/abs/10.3171/2014.8.FOCUS14381)

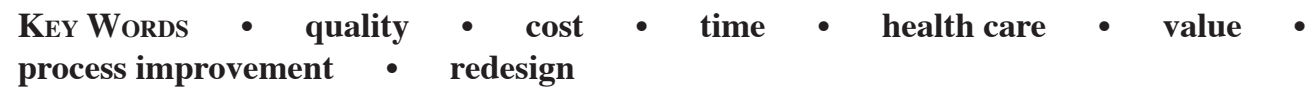

I

$\mathrm{N}$ the last decade, programs targeting safety, risk management, and quality of care have spread across the nation. ${ }^{1,26,31}$ Many organizations are now reporting outcome data to national organizations. ${ }^{20,30}$ Extending this progress, Porter et al..$^{14,27-29}$ have led the advocacy that the central focus for health care systems should be to deliver a high value of care, with value determined by outcomes achieved and costs incurred. Although care providers have taken the lead in making patient outcomes, such as safety and quality of care, an overarching goal, they have been far less engaged in cost measurement and contain-

Abbreviations used in this paper: $\mathrm{BPH}=$ benign prostatic hyperplasia; FTE = full-time equivalent; MVD = microvascular decompression; $\mathrm{OR}=$ operating room; $\mathrm{TDABC}=$ time-driven activitybased costing ment. Nuanced perceptions of providers' responsibility to reduce cost, a lack of knowledge of health economics, and the absence of accurate and actionable cost data available at the provider level have contributed to the disappointing lack of progress in cost-measurement and cost-reduction initiatives. ${ }^{8,9,32}$

Policy makers refer to "cost" as the payments made to health care providers for delivering care. For providers, however, cost refers to the amounts they pay for personnel, equipment, supplies, and facilities to deliver patient care. Although traditional hospital cost-accounting systems measure costs well at the level of operating and support (overhead) departments, they do an inadequate job when allocating costs from organizational units down to the actual care processes used to treat patients. ${ }^{14}$ In addition, the assignment of physician service costs using methods such 
as the ratio of costs to charges (RCC) or the Medicare resource-based relative value scale (RBRVS) has been criticized heavily regarding its allocation methodology and calibration. ${ }^{3,11,19}$ Therefore, an updated, unified, reliable, and transparent method of measuring the costs of hospital- and physician-related services is needed. ${ }^{33}$

Recently, time-driven activity-based costing (TDABC) has gained popularity in health economics as an accurate costing methodology that provides clinicians and staff with valid, actionable process and cost data to redesign care effectively. ${ }^{10,12-14}$ TDABC estimates, from the provider's perspective, the cost of each resource used for treating a patient's medical condition and combines it with the time each resource uses for each activity during a patient's care. ${ }^{13}$ All of these activities can then be added together to measure the total cost of an entire service or care episode.

Under the mentorship of the Harvard Business School and in collaboration with local clinician sponsors, 2 teams at UCLA Health (UCLA) piloted the TDABC model in service lines that already had ongoing value-improvement and care-redesign projects. One team studied the microvascular compression syndrome (trigeminal neuralgia, hemifacial spasm, glossopharyngeal neuralgia) service line (neurosurgery pilot). ${ }^{21,22}$ This service line treats rare conditions for which the UCLA Department of Neurosurgery is a referral center (providing tertiary and quaternary care). The second team studied the benign prostatic hyperplasia (BPH) service line (urology pilot). This is a prevalent condition treated with substantial practice pattern variation and is managed by primary care physicians (primary care) and specialists (secondary care).

In this paper, we detail the steps of experimentation and implementation of the TDABC methodology, share lessons learned across the care continuum, and report how this model has succeeded in engaging health care providers in process assessment and costing activities.

\section{Selecting the Pilots}

The pilot projects were launched after a neurosurgeon (N.M.) and an executive director (D.R.N.) attended the Harvard Business School course "Implementing Cost Management in Health Care." Their goals were to integrate the TDABC methodology into service lines that were interested in analyzing cost across the continuum of care, specifically those already engaged in outcome measurement and care redesign. They met with the institution's leadership to: 1) present the TDABC model as an innovative tool that calculates the cost of care delivery using a standard approach integrating hospital-related and physician service-related costs and 2) ensure their support for this initial experimentation phase.

\section{Neurosurgery Pilot}

The neurosurgery team launched a multidisciplinary and multidepartmental care-redesign initiative designed initially to be piloted in 4 elective patient populations, one of which was a population of patients with microvascular compression syndrome undergoing microvascular decompression (MVD). ${ }^{22,23}$ Process mapping was the first step, which was essential for capturing the current state of care delivery. Initial data on general outcomes and condition-specific outcomes were obtained by detailed manual chart review and were organized using the outcome hierarchy methodology proposed by Porter. ${ }^{28}$ After a comprehensive quality improvement initiative that resulted in improved outcomes in the MVD service line, the neurosurgery team aimed to develop a cost-containment initiative using current decision-support hospital-related cost data. ${ }^{22,25}$ Although the use of these costing data may have worked well in the past, it did not integrate the cost of physician services and its continued use in the near future will be challenging, because the Affordable Care Act requires providers to participate in shared or "bundled" reimbursements among multiple parties and potentially across the continuum of care.

\section{Urology Pilot}

Members of the urology team convened a multidisciplinary group to identify the many paths that a patient with $\mathrm{BPH}$ may take through the course of his treatment. ${ }^{7}$ They mapped the processes along each potential care pathway and captured the key decision points. General and condition-specific outcomes of importance to the patient were linked to each pathway. The urology pilot team considered analyzing charges using the institution's decision-support financial system but, after the introduction of TDABC, recognized that this methodology offered a more comprehensive approach at identifying true costs across the patient's entire journey through the health system.

The executive director, who participated in both the urology and neurosurgery projects, noted differences in the sequences of steps and the level of detail within maps of the perioperative phases of care. The 2 teams met and agreed to standardize the level of detail in both initiatives and to adopt a common approach for costing.

\section{Creating a TDABC Team Within the Institution}

The team leading the TDABC initiative (the TDABC team) was composed of 1 clinician (N.M.), 1 executive director (D.R.N.), and 2 internal consultants (M.A.B. and N.P.S.) (Fig. 1). The 2 internal consultants (termed the TDABC coaches in subsequent sections of this paper) integrated the team given: 1) their interest in improving care delivery; 2) their knowledge of health economics; 3 ) the attribution, by leadership, of protected time to work on this project; and 4) their depth of knowledge and skill sets in performance improvement. This collaboration describes the merging of clinical and operational efforts, coined "clinical operations."

\section{Getting Organized Within the Pilots}

The neurosurgery pilot organized education regarding the TDABC process via small groups of care providers that worked together on either the same activity (e.g., physiotherapists) in the same location (e.g., clinic medical assistants) or on the same phase of care (e.g., operating room [OR] staff). For the urology pilot, the TDABC team educated the multidisciplinary urology team about 


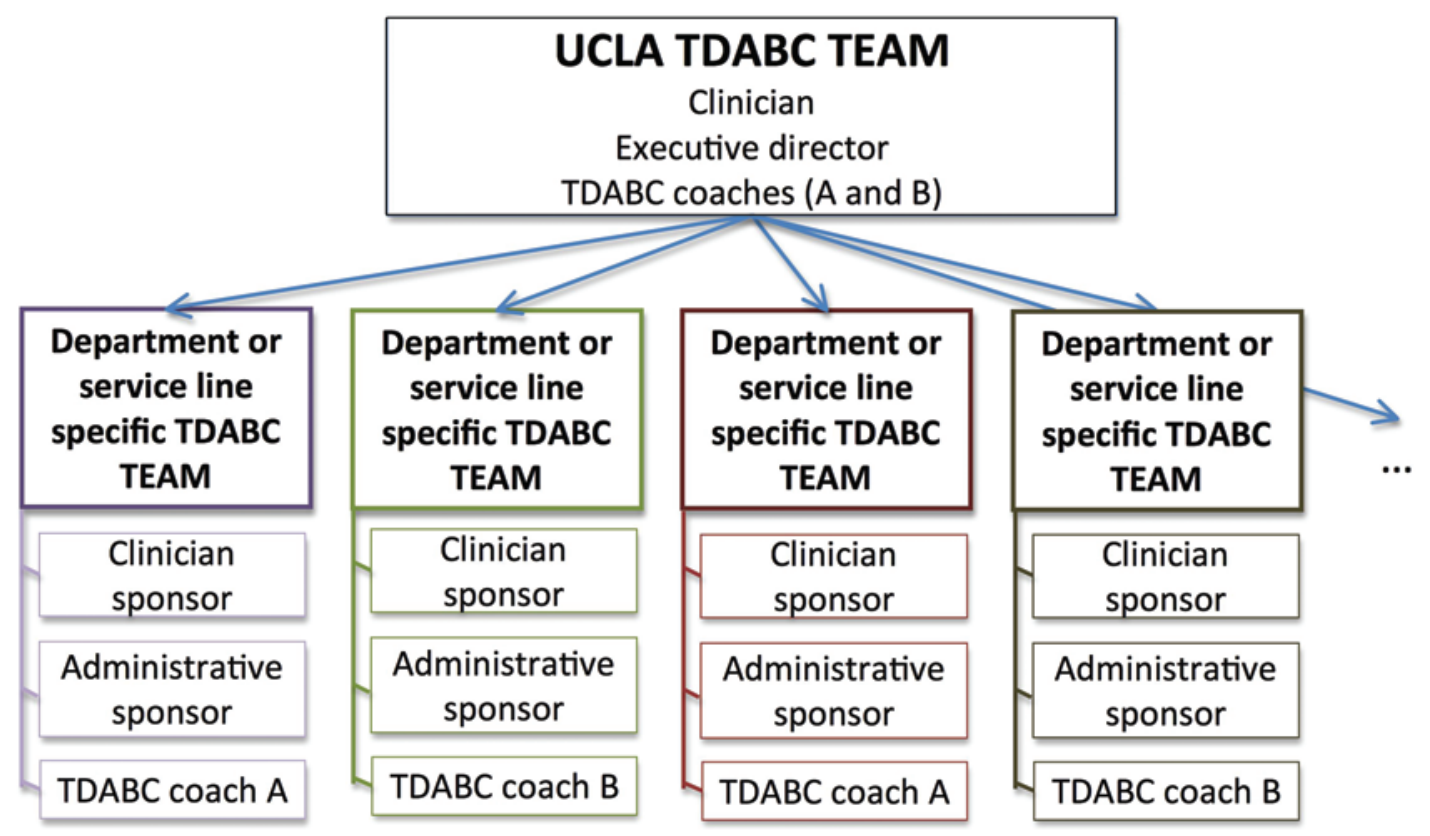

Fig. 1. Structure of the TDABC team and oversight of the pilot projects.

the new costing methodology. Both pilots worked from TDABC templates obtained at the Harvard Business School training session. ${ }^{13}$

In both pilots, a physician sponsor (N.M., N.A.M., C.S., or A.M.) was identified and joined by an administrative sponsor (either the department's administrator, clinical director, executive director, or department manager). The requirements for the administrative sponsor included comprehensive knowledge of the nuances of the department's finances and easy access to financial data. The physician and administrative sponsors were paired with a TDABC coach. The TDABC coaches had the capacity to facilitate conversations and assist in the use of processimprovement tools, such as process mapping, and benefited from their existing relationships with key stakeholders across the institution. The clinical and executive TDABC advisors contributed by introducing TDABC to current quality improvement initiatives within the institution, addressing internal barriers and resolving any procedural issues, and steering the work of the TDABC coaches.

\section{Mapping the Episode of Care}

Process mapping within the TDABC model captured the current state of the process and its associated costs. For each pilot, clinicians, administrative staff, and other contributing health care providers were brought together to complete a process map with the following inputs: process steps, decision points, resources involved in the activity (including human, material, and equipment resources), time spent doing the activity, and the variability around each input. The teams identified each step from the patients' and staff members' perspectives and created a map to reflect the paths and sequences of work they described. The actual mapping sessions afforded excellent opportunities to educate providers on the new TDABC system that was being tested, to have providers relate to their own impact on cost generation, and to engage providers in cost-measurement and -containment initiatives.

Both pilots started by creating a high-level map to represent the global sequence of events throughout the entire episode of care (Fig. 2). A modified Delphi technique was used. The mapping sessions began with preselected items (high-level process maps), and although the selected content experts were questioned face-to-face throughout the mapping activity, the key stakeholders were consulted by email by members of the TDABC team for final approval.6,18 The key stakeholders, including frontline staff, department managers, and unit directors, validated the process maps once they were in their detailed and final form.

For the duration of each activity, the pilot teams captured the times spent in each activity from one of the following: 1) actual documented activity times extracted from the electronic medical record system; 2) time studies/observational studies; 3) average estimates with minimum and maximum values; or 4) average self-reported data. Electronic medical records provided a wealth of transactional details regarding location, duration, and provider, from which the true patient costs were calculated using TDABC. Multiple care providers independently verified the time values to ensure that they were clinically sound.

\section{Coordinating Capacity-Cost Calculation}

Reviewing the maps for the entire episodes of care, varying types of personnel involved in the delivery of care were noted. The total numbers of different types of personnel involved in the care delivery of both the neurosurgery and urology pilots were 63 and 61, respectively.

The TDABC executive advisor, also the executive director of operative services, reviewed the TDABC model 


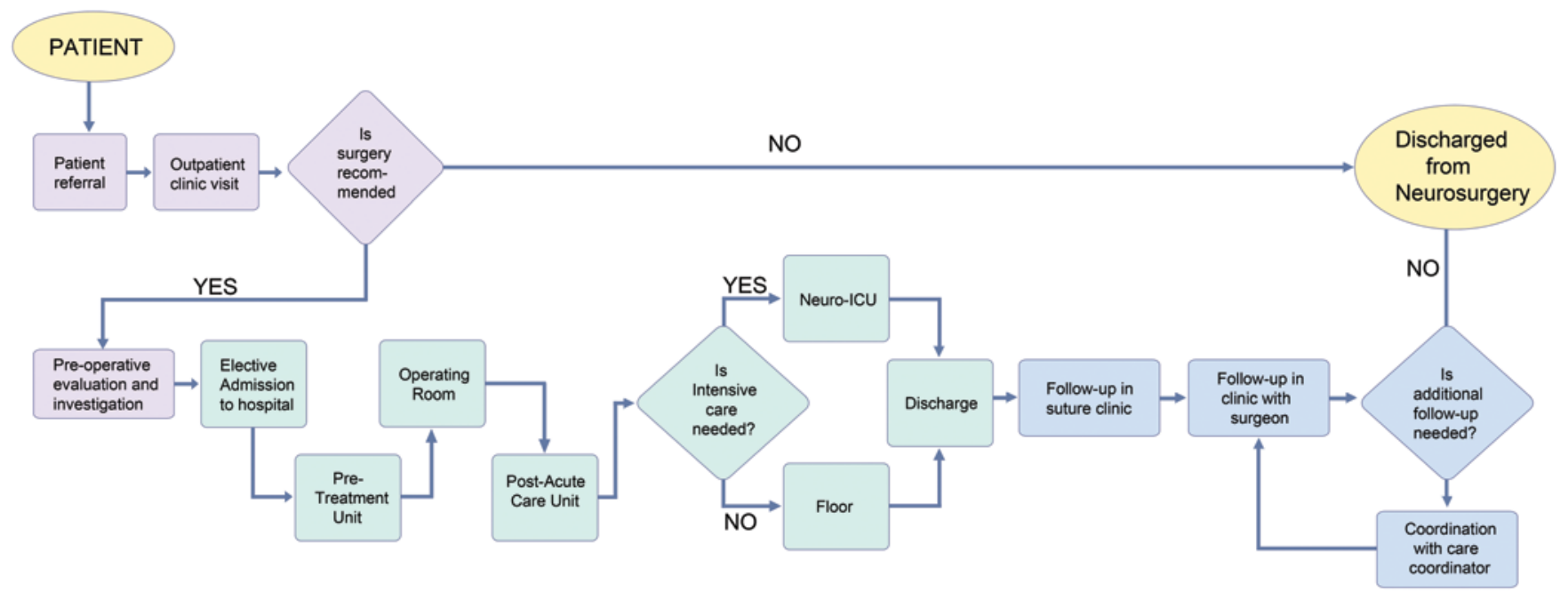

FIG. 2. Example of a high-level process map for a patient undergoing neurosurgery. Outpatient preoperative steps are indicated in purple, inpatient perioperative steps in green, and outpatient postoperative steps in blue.

with the OR performance manager, who developed a personnel-costing template (Table 1), approved the finalized process maps, and addressed potential pitfalls. The OR performance manager collected the financial data within 1 week. After verification of the data, very few corrections had to be made. The OR staff capacity-cost exercise served as a template to help standardize the development of the financial model. After completion of the process maps, the TDABC coaches introduced the personnelcosting template and reviewed the methodology for calculating each care provider's capacity cost. The TDABC coaches coordinated follow-up meetings within 2 weeks to review the progress made regarding clinical capacity assessment and financial data gathering (Fig. 3).

\section{Pearls and Pitfalls to Calculating Capacity Cost for Care Coordinators/Clinical Assistants}

Care coordinators and clinical assistants in the University of California system are paid on the basis of seniority levels within their classification. Each department's administrative sponsor provided the average salary using the UCLA human resource salary tables. Time capacity was determined by the University of California work policies regarding holidays, vacation, sick leave, and daily hours. Each department's budget had specific line items with allocated expenses for information technology support and supplies. The allocated expense was divided evenly by the number of full-time equivalents (FTEs). Obtaining the capacity-cost rate for the care coordinators was straightforward with a standard methodology that was replicable throughout the departments. This method was used to calculate the capacity cost of all support staff and hourly employees, with the exception of nurses.

\section{Pearls and Pitfalls to Calculating Capacity Cost for Inpatient Nurses}

Capacity-cost calculations for nursing were more complex. The personnel costing template was used to capture all the different classifications of health care providers categorized under "nursing" and "support staff." For nursing, we identified 6 types of health care providers that have similar care functions toward patients: adult nurse I (ANI), clinical nurse I (CNI), CNII, CNIII, per-diem registered nurse (RN), and per-diem resource RN. For support staff, we identified 3 classifications of health care providers providing support care: care partners (CPs), licensed vocation nurses, and hospital assistants. As the model was built, the nurse-to-patient ratio was taken into consideration. In California, this ratio is mandated by law (e.g., 1:4 on floor units and 1:2 on intensive care units). As recommended by the Harvard Business School coaches, the nursing ratio, not time spent with the patient, was used because of the vari-

TABLE 1: Personnel costing template*

\begin{tabular}{lccccccc}
\hline \multicolumn{7}{c}{ [Enter Department Name] TDABC Personnel Costing Template } \\
\hline Title Code & Level & $\begin{array}{c}\text { Average Hourly } \\
\text { Rate }(\$)\end{array}$ & $\begin{array}{c}\text { Total Paid } \\
\text { FTE }\end{array}$ & $\begin{array}{c}\text { Weighted } \\
\text { \% Weight }\end{array}$ & $\begin{array}{c}\text { Total Hours } \\
\text { Average }\end{array}$ & $\begin{array}{c}\text { Total Salary } \\
\text { Worked per Yr }\end{array}$ & per Yr (\$) \\
\hline staff supervisor & ANI & 40.00 & 2 & 100 & 40.00 & 2088 & $167,040.00$ \\
staff & 1 & 30.00 & 3 & 30 & & 2088 & \\
& 2 & 32.00 & 2 & 20 & 32.40 & 2088 & $67,651.20$ \\
& 3 & 34.00 & 5 & 50 & & 2088 & \\
\hline
\end{tabular}

\footnotetext{
${ }^{*} \mathrm{ANI}=$ adult nurse $\mathrm{I}$.
} 

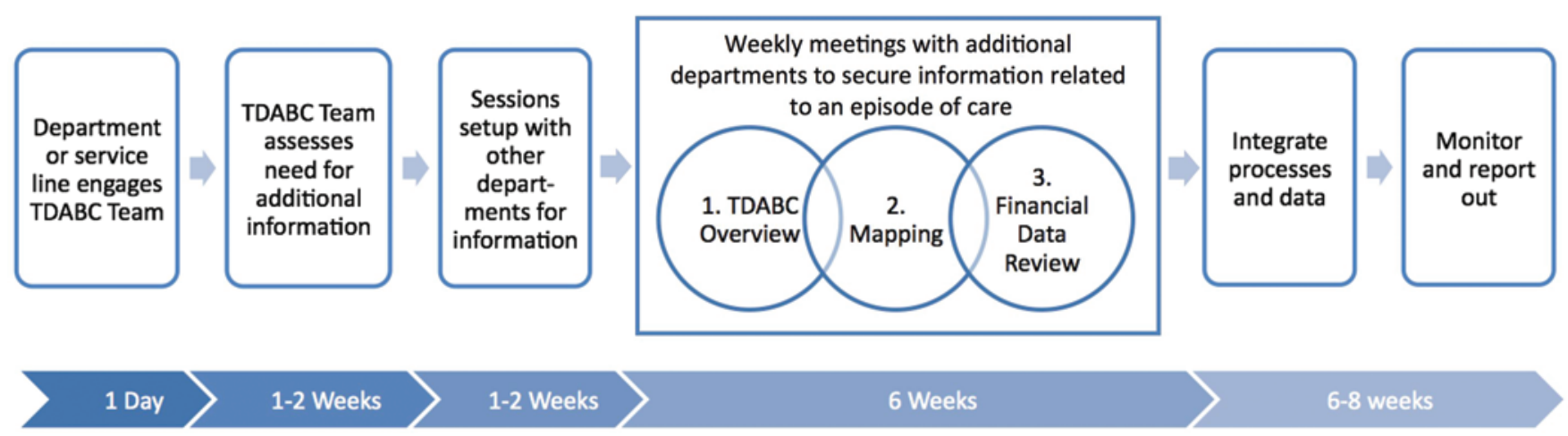

FIG. 3. Timeline of the TDABC experiment and implementation.

ability in patient needs and the inability to predict need..$^{13,14}$ In addition to the bedside nursing, charge nurses and nurse managers were also captured with a nurse-to-patient ratio of 1:24. Because they were readily available to help in direct bedside delivery of care, in addition to their administration duties for the unit, their capacity cost was included in the TDABC model. ${ }^{13,14}$ We identified the nursing units through which our pilot populations would navigate their care by reviewing the process map. The director of nursing finance completed a personnel costing template (Table 1) and provided a weighted average compensation rate for each unit. It should be noted that the shift differentials, overtime pay for nights and weekends, were not included in our model. In our institution, inpatient nursing staff work three 12-hour shifts per week and have a total of 75 minutes per shift for breaks and meals.

For each unit, the unit director was considered as supervisor for all nursing staff in the unit. The unit director's salary was divided by the total number of FTEs supervised. As an example, the amounts per FTE supervised were \$5148 in the neurosurgical ICU, \$7324 in the neurosurgical floor unit, and $\$ 8015$ in the urology floor unit.

\section{Pearls and Pitfalls to Calculating Capacity Cost for Faculty Physicians}

\section{XYZ Compensation}

The physician compensation plan was founded on a traditional academic model, which includes base salary as set forth in standardized salary scales, negotiated additional compensation, and incentive compensation. In some instances, attending faculty may receive administrative stipends and outside income, adding to the total compensation. In calculating clinical capacity-cost rates for the application of TDABC at UCLA, the TDABC team interviewed the administrative sponsor of each clinical department to gain an understanding of the variation in physician compensation within and across the departments. Largely, the variation existed because of differences in the practice models across the departments.

\section{Practice Plan Models}

One common method of calculating incentive compensation is through a physician-specific profit-and-loss financial statement. In this approach, incentive compen- sation is allocated to an individual by calculating the operating margin, which equals the practice net revenues (ie, professional fees, outside income, administrative stipends, grant funding, etc.) less the practice operating expenses (i.e., base salary and benefits, clinic expenses, malpractice, office supply, travel, etc.). The remaining net operating margin is then distributed as incentive compensation, beyond the base salary and negotiated additional compensation. This approach was used for both surgical departments (urology and neurosurgery).

For primary care and anesthesiology, the physicians are paid a negotiated, guaranteed salary based on a specific level of relative value unit (RVU) productivity. If their actual RVU productivity fluctuates below or above the negotiated level, then their salary will be renegotiated the next year or they will receive an incentive payment, accordingly.

Similarly, for anesthesiology, physicians are paid a guaranteed salary that is based on a commitment to provide a negotiated number of clinical assignments per week averaged over the year. Typically, 8 hours of clinical work constitutes a clinical assignment, with additional hours worked in a day compensated as incentive pay. Clinical work, in the form of extra clinical assignments, is also compensated as incentive pay.

\section{Clinical Hour Capacity}

Physician capacity varied greatly across the 5 specialties that we surveyed. Capacity includes the total amount of time a provider is available to work on patient care-related activities in any given year. Examples of times that were often not immediately thought of by clinicians as patient-related care were chart reviews at home and monitoring patients from the office (Table 2). Excluding these activities from physician capacity caused a significant increase in the physician capacity-cost rate. The value for the physician salaries is the average of the service or department for a representative faculty member/attending physician.

\section{Ensuring Buy-In of the Personnel Capacity Cost}

Although capacity costs were gathered for all the resources (including material, equipment, and space) used within both pilots, personnel costs represent more than $50 \%$ of all incurred costs to deliver care. Given that the capacity-cost value (\$/minute) for each type of personnel 
TABLE 2: Example of activities and related costs uniquely captured by the TDABC model

\begin{tabular}{lclcr}
\hline \multicolumn{1}{c}{ Role } & Capacity-Cost Rate (\$) & \multicolumn{1}{c}{ Task } & Time (mins) & Total (\$) \\
\hline neurosurgeon & 3.22 & chart review & 10 & 32.2 \\
urologist & 2.95 & rounding & 10 & 29.50 \\
neurologist & 2.29 & monitor cases remotely & 301 & 689.29 \\
neurotechnology director & 2.27 & review \& schedule cases & 18 & 40.86 \\
neurosurgery nurse practitioner & 1.17 & review preop documents & 37.5 & 43.88 \\
OR scheduler & 0.63 & fill excess block time & 5 & 3.15 \\
\hline
\end{tabular}

is new to the institution, it was essential to have different stakeholders validate their capacity costs. Indeed, once different capacity costs were presented to multiple health care providers (including different physician specialists), the providers asked: "What elements are driving the difference between the capacity cost of personnel type A versus B?" More specifically for physician capacity costs, significant drivers of this variation included clinical hours per day, holiday time per year, weekend days available per year, call-back time per month, and education time per year (Table 3).

After reviewing the TDABC methodology and the capacity-cost templates with the clinician and administrative sponsors, the teams designed a checklist of key questions to consistently stimulate physicians' reflection on all patient-related activities performed that should be captured as they estimated their clinical capacities. After going through this verification process, the capacity costs decreased $\$ 1.34$ (from $\$ 4.29$ to $\$ 2.95$ ) for urology and $\$ 0.76$ (from $\$ 3.98$ to $\$ 3.22$ ) for neurosurgery and increased $\$ 0.70$ (from $\$ 3.21$ to $\$ 3.91$ ) for anesthesia.
Through the interview process with the attending physicians, a range from 105,000 clinical minutes (approximately 8 hours/day, 5 days/week) to 165,000 clinical minutes (approximately 10.5 hours/day, 6 days/week) was highlighted. To understand the impact that the variation in annual clinical available minutes has on the total cost of care, a sensitivity analysis was conducted using the maximum and minimum capacity-cost rates shown in Fig. 4. For the neurosurgery pilot, the impact was about 9\% around the calculated cost (Fig. 4).

A work session involving all clinical champions, department or service chairs, and their financial administrators was coordinated to review the TDABC methodology pertaining to personnel capacity-cost calculations for physicians. Although a standard methodology is required to ensure consistency within the institution, the need for some customization was recognized, enabling us to capture various specialty business models within the institution. Consensus among the members of this committee was achieved, ensuring buy-in from all specialties involved in both pilot programs.

\section{TABLE 3: Drivers of different capacity-cost calculations*}

\begin{tabular}{|c|c|c|c|c|c|}
\hline Driver & $\begin{array}{c}\text { Neurosurgery } \\
\text { Attending Physician }\end{array}$ & $\begin{array}{c}\text { Anesthesiology } \\
\text { Attending Physician }\end{array}$ & $\begin{array}{l}\text { Neurology Attending } \\
\text { Physician }\end{array}$ & $\begin{array}{l}\text { Urology Attending } \\
\text { Physician }\end{array}$ & $\begin{array}{l}\text { Primary Care } \\
\text { Provider }\end{array}$ \\
\hline total days/yr & 365 & 365 & 365 & 365 & 365 \\
\hline (-)weekends & 78 & 104 & 78 & 104 & 104 \\
\hline (-)holidays & 13 & 13 & 13 & 13 & 13 \\
\hline (-)vacation & 10 & 20 & 10 & 10 & 10 \\
\hline (-)sick \& personal leave & 3 & 3 & 3 & 2 & 5 \\
\hline (-)CME \& conferences & 10 & 5 & 10 & 9 & 5 \\
\hline available clinical days/yr & 251 & 220 & 251 & 227 & 228 \\
\hline total mins at work/day & 720 & 480 & 720 & 630 & 540 \\
\hline (-)breaks, training, \& non-patient meetings & 90 & 0 & 90 & 30 & 30 \\
\hline (-)research, education, \& administrative time & $0 \dagger$ & 0 & 0 & 0 & 35 \\
\hline available clinical mins/day & 630 & 480 & 630 & 600 & 475 \\
\hline days on call/yr & 28 & 29 & 73 & 30 & 12 \\
\hline days on call called back & 9 & 0 & 0 & 6 & 0 \\
\hline mins actually working when on call & 480 & 180 & 203 & 240 & 100 \\
\hline available clinical mins/yr & 162,450 & 110,683 & 172,962 & 137,469 & 109,364 \\
\hline
\end{tabular}

* $\mathrm{CME}=$ continuing medical education.

$\dagger$ For these types of physicians, research time was excluded from the capacity-time calculation because the funds supporting research were also excluded from salary. 

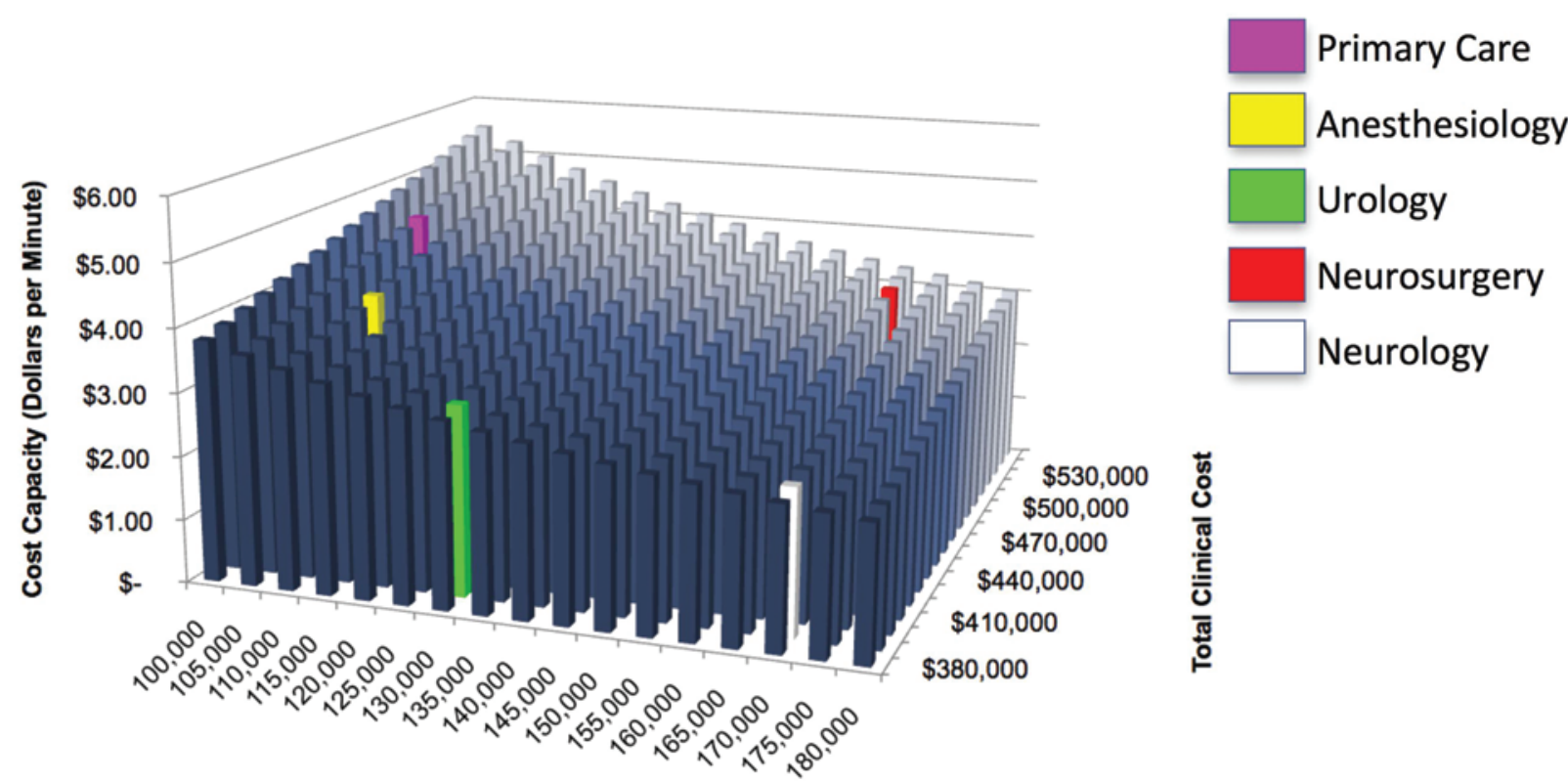

105,000 clinical minutes $=$ approx. 8 hours/day, 5 days/week

\section{Annual Clinical Availability (Minutes) for Physicians}

165,000 clinical minutes $=$
approx. 10.5 hours/day, 6 days/week

FIG. 4. Sensitivity analysis of capacity-cost rates for physicians.

\section{The TDABC Model: A Catalyzing Tool for Integration}

\section{Level I: Integration of Processes and Costs}

The TDABC model enabled the linking of a specific step of the care cycle (who performed the step and its duration) and its associated costs, including personnel, material, equipment, and space costs (Fig. 5). ${ }^{4,10,12-15}$ This costing model enabled variability assessment among health care providers' delivery of care throughout an entire episode of care. At the activity level, it enabled the identification of duplications of steps, unnecessary steps, rework loops, sources of delays, and role ambiguity (in which 2 types of personnel could perform 1 step but with different cost capacities), which are all high-yield opportunities. ${ }^{24}$ At the resource level, TDABC provided clarity regarding unused, underused, and overused personnel, space, and equipment from a provider perspective.

Integration of the processes and their associated costs enabled teams to design cost-efficient care delivery. In the preoperative clinic setting, redesign strategies included engaging medical assistants and nurse practitioners to work at the highest level of their role, enabling the physician to dedicate his or her time to do what only he or she can do: discuss the medical condition, review management options, and establish a patient-centered plan. In the in-hospital setting, multidisciplinary teams have been initiating care-redesign strategies around specific care points such as pain management, urination, and mobilization. For a process metric, intermediate outcome measure, or clinical outcome measure (eg, ambulating 50 feet by noon on postoperative day 1), TDABC cost estimates were used to select the most cost-efficient redesign option to satisfy the measure. In the postoperative clinic setting, redesign strategies included evaluating alternative follow-up approaches, such as nurse telephone clinics, telemedicine, and electronically monitored patient-reported symptom scores. The TDABC costing model supports a dynamic process, with potentially multiple cycles dedicated to calculating the cost impact of the redesign options, assessing potential implications for steps down the map, and determining the cost impact of secondary implications.

\section{Level II: Integration of Clinical, Operational, and} Financial Teams

In many health care institutions, there has historical-

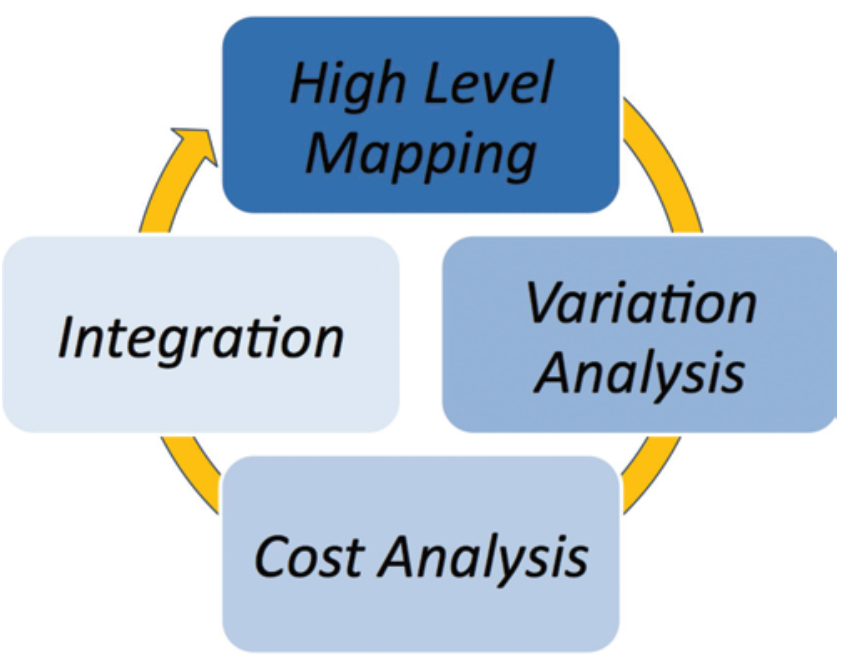

FIG. 5. Key steps of the TDABC model. 
ly been a disconnect between the detailed representation of clinician or staff activities in a care-pathway process map and the level of detail in the costs assigned to such activities by the institution's traditional cost-accounting system. The pairing of service line clinical and administrative sponsors with TDABC coaches and advisors, who were versed in the TDABC methodology, enabled the 2 pilot teams to match detailed costing and resource utilization information with provider activity-level detail across the continuum of care from the patient perspective. The methodology provided not only transparency and integration of clinical, financial, and operational information but also facilitated the development of a new multidisciplinary team unit (clinical operations) essential to any redesign initiative. . $^{12,14,33}$

\section{Level III: Integration of TDABC Model Within the Institution}

Although the identification of apparent opportunities to improve outcomes and reduce costs may result in some important gains, the next great leap in improved care delivery will require a more systematic and detailed review of the entire episode of care, linking processes and costs from TDABC with clinical outcomes and patient satisfaction data. ${ }^{5,16}$ UCLA has been visionary in identifying innovative tools and coordinating teams that master these tools to guide and support its members' initiatives in care redesign. After integration and standardization of the TDABC methodology, an institution can position itself to transform care delivery in a cost-conscious fashion and achieve the "triple aim." rate and actionable process and cost data to clinicians and truly engaged them in costing activities and care redesign within service lines, departments, and institutions.

\section{Conclusions}

The experimentation and implementation phases of the TDABC model in the neurosurgery MVD and urology BPH pilots have succeeded in engaging health care providers, not only within these departments but also throughout the organization, in process assessment and costing activities. The TDABC model proved to be a catalyzing agent for care redesign, getting everyone at the same table, to understand and agree upon the care-delivery process and to realize the true costs of the resources needed to perform each activity. ${ }^{13,14}$ TDABC has shown great potential to steer cost-conscious care-delivery transformation and health system performance optimization.

\section{Acknowledgments}

We express our gratitude to the following UCLA teams for their help: CareConnect (Michael Pfeffer), Department of Anesthesiology (Catherine Duda), Department of Neurology (Marie Webber, Pedro Churchill, Marc Nuwer), Department of Neurosurgery (Steve Cohen), Department of Nursing (Betty Wilber, Cathy Ward), Department of Radiology, Department of Urology (Kelli Baker, Laura Baybridge), Environmental Services (Andrei Roudenko), Facilities (Val Padilla), Financial Services (Deborah Chandler, Andrew Kaufman), Faculty Practice Group (Robin Clarke, Jeff Butler), Harvard Business School (Samuel Weirtheimer), Health System Leadership (Shannon
O'Kelley, Paul Staton, Tom Rosenthal), Materials Management (Michael Baca), Clinical Engineering (Vigen Esmailian), Operative Services (Diana Rempel, Chris Pizzulli, Donna Felix, Jasmine Briones), Performance Excellence (Mark Mayes), Real Estate (Richard Azar), and Rehabilitation Services (Cindy Jaeger, Ellen Wilson, Jeff Davis). We also express our gratitude to Samuel Weitheimer from the Harvard Business School.

\section{Disclosure}

The authors report no conflict of interest concerning the materials or methods used in this study or the findings specified in this paper.

Author contributions to the study and manuscript preparation include the following. Conception and design: McLaughlin, Burke, Setlur, Niedzwiecki, Saigal, Kaplan. Acquisition of data: McLaughlin, Burke, Setlur, Niedzwiecki, Kaplan. Analysis and interpretation of data: McLaughlin, Burke, Setlur, Niedzwiecki, Kaplan, Saigal, Mahajan, Martin. Drafting the article: McLaughlin, Burke, Setlur, Niedzwiecki. Critically revising the article: all authors. Reviewed submitted version of manuscript: McLaughlin, Burke, Setlur, Niedzwiecki. Approved the final version of the manuscript on behalf of all authors: McLaughlin. Study supervision: McLaughlin.

\section{References}

1. Afsar-Manesh N, Martin NA: Healthcare reform from the inside: a neurosurgical clinical quality program. Surg Neurol Int 3:128, 2012

2. Bisognano M, Charles K: Leadership for the triple aim. Threepronged framework helps executives lead quality initiatives. Healthc Exec 27:80, 82-83, 2012

3. Cooper R, Kramer TR: RBRVS costing: the inaccurate wolf in expensive sheep's clothing. J Health Care Finance 34:6-18, 2008

4. Demeere N, Stouthuysen K, Roodhooft F: Time-driven activity-based costing in an outpatient clinic environment: development, relevance and managerial impact. Health Policy 92: 296-304, 2009

5. DiGioia AM III, Greenhouse PK: Care experience-based methodologies: performance improvement roadmap to value-driven health care. Clin Orthop Relat Res 470:1038-1045, 2012

6. Falzarano M, Pinto Zipp G: Seeking consensus through the use of the Delphi technique in health sciences research. J Allied Health 42:99-105, 2013

7. Gilbert SM, Sanda MG, Dunn RL, Greenfield TK, Hembroff L, Klein E, et al: Satisfaction with information used to choose prostate cancer treatment. J Urol 191:1265-1271, 2014

8. Ginsburg ME, Kravitz RL, Sandberg WA: A survey of physician attitudes and practices concerning cost-effectiveness in patient care. West J Med 173:390-394, 2000

9. Goold SD, Hofer T, Zimmerman M, Hayward RA: Measuring physician attitudes toward cost, uncertainty, malpractice, and utilization review. J Gen Intern Med 9:544-549, 1994

10. Hennrikus WP, Waters PM, Bae DS, Virk SS, Shah AS: Inside the value revolution at Children's Hospital Boston: timedriven activity-based costing in orthopedic surgery. Harvard Orthopedic J 14:40-47, 2012

11. Hsiao WC, Braun P, Dunn DL, Becker ER, Yntema D, Verrilli DK, et al: An overview of the development and refinement of the Resource-Based Relative Value Scale. The foundation for reform of U.S. physician payment. Med Care 30 (11 Suppl): NS1-NS12, 1992

12. Inverso G, Lappi MD, Flath-Sporn SJ, Heald R, Kim DC, Meara JG: Increasing value in plagiocephaly care: a timedriven activity-based costing pilot study. Ann Plast Surg [epub ahead of print], 2013

13. Kaplan RS, Anderson SR: Time-driven activity-based costing. Harv Bus Rev 82:131-138, 150, 2004 
14. Kaplan RS, Porter ME: How to solve the cost crisis in health care. Harv Bus Rev 89:46-52, 54, 56-61, passim, 2011

15. Lee MH, Schuur JD, Zink BJ: Owning the cost of emergency medicine: beyond 2\%. Ann Emerg Med 62:498-505.e3, 2013

16. Lee TH: Care redesign - a path forward for providers. N Engl J Med 367:466-472, 2012

17. Levine JF, Herbert B, Mathews J, Serra A, Rutledge V: Use of the Triple Aim to improve population health. N C Med J 72: 201-204, 2011

18. Logue MD, Effken JA: Validating the personal health records adoption model using a modified e-Delphi. J Adv Nurs 69:685-696, 2013

19. Maloney JV Jr: A critical analysis of the resource-based relative value scale. JAMA 266:3453-3458, 1991

20. McCrum ML, Joynt KE, Orav EJ, Gawande AA, Jha AK: Mortality for publicly reported conditions and overall hospital mortality rates. JAMA Intern Med 173:1351-1357, 2013

21. McLaughlin N, Afsar-Manesh N, Ragland V, Buxey F, Martin NA: Tracking and sustaining improvement initiatives: leveraging quality dashboards to lead change in a neurosurgical department. Neurosurgery 74:235-243, 2014

22. McLaughlin N, Buxey F, Chaw K, Martin NA: Value-based neurosurgery: the example of microvascular decompression surgery. Clinical article. J Neurosurg 120:462-472, 2014

23. McLaughlin N, Carrau RL, Kelly DF, Prevedello DM, Kassam AB: Teamwork in skull base surgery: an avenue for improvement in patient care. Surg Neurol Int 4:36, 2013

24. McLaughlin N, Rodstein J, Burke MA, Martin NA: Demystifying process mapping: a key step in neurosurgical quality improvement initiatives. Neurosurgery 75:99-109, 2014

25. McLaughlin N, Upadhyaya P, Buxey F, Martin NA: Valuebased neurosurgery: measuring and reducing the cost of microvascular decompression surgery. Clinical article. J Neurosurg 121:700-708, 2014
26. Peterson TH, Teman SF, Connors RH: A safety culture transformation: its effects at a children's hospital. J Patient Saf 8: 125-130, 2012

27. Porter ME: A strategy for health care reform-toward a valuebased system. N Engl J Med 361:109-112, 2009

28. Porter ME: What is value in health care? N Engl J Med 363: 2477-2481, 2010

29. Porter ME, Pabo EA, Lee TH: Redesigning primary care: a strategic vision to improve value by organizing around patients' needs. Health Aff (Millwood) 32:516-525, 2013

30. Rodrigues R, Trigg L, Schmidt AE, Leichsenring K: The public gets what the public wants: experiences of public reporting in long-term care in Europe. Health Policy 116:84-94, 2014

31. Shojania KG, Duncan BW, McDonald KM, Wachter RM, Markowitz AJ: Making health care safer: a critical analysis of patient safety practices. Evid Rep Technol Assess (Summ) 2001:i-x, 1-668, 2001

32. Tilburt JC, Wynia MK, Sheeler RD, Thorsteinsdottir B, James KM, Egginton JS, et al: Views of US physicians about controlling health care costs. JAMA 310:380-388, 2013

33. Vogl M: Improving patient-level costing in the English and the German 'DRG' system. Health Policy 109:290-300, 2013

Manuscript submitted June 26, 2014.

Accepted August 18, 2014.

Please include this information when citing this paper: DOI: 10.3171/2014.8.FOCUS14381.

Address correspondence to: Nancy McLaughlin, M.D., Ph.D., F.R.C.S.C., Department of Neurosurgery, David Geffen School of Medicine, 757 Westwood Plaza, Ste. 6236, Los Angeles, CA 900957436.email: nmclaughlin@mednet.ucla.edu. 